\title{
Evaluation of the Mechanical Properties of ZnO Nanorods Treated with Oxygen Plasma using Atomic Force Microscopy
}

\author{
Donghyuck Park, Yijun Yang, and Kwanlae Kim* \\ Department of Manufacturing Systems and Design Engineering, Seoul National University of \\ Science and Technology, Seoul 01811, Republic of Korea
}

\begin{abstract}
Zinc oxide ( $\mathrm{ZnO})$ simultaneously exhibits semiconducting and piezoelectric properties. $\mathrm{ZnO}$ in the form of nanorods has been studied intensively for application in self-powering devices. The power generation in piezoelectric nanogenerators based on $\mathrm{ZnO}$ nanorods can be improved via several approaches, including an oxygen plasma treatment. When $\mathrm{ZnO}$ nanorods are exposed to oxygen plasma, the charge carrier concentration decreases and the piezoelectric output voltage consequently increases. However, the effects of oxygen plasma on the mechanical properties of $\mathrm{ZnO}$ nanorods has not been systematically studied using a precise measurement technique. Given the size of $\mathrm{ZnO}$ nanorods, atomic force microscopy (AFM) is a suitable method for manipulating individual $\mathrm{ZnO}$ nanorods and measuring their elastic properties. In the present work, we observed the effects of oxygen plasma on the elemental composition and microstructure of $\mathrm{ZnO}$ nanorods. First of all, the surface roughness of the $\mathrm{ZnO}$ nanorods was analyzed using AFM, revealing that it increased due to the etching effect of the oxygen plasma. From X-ray photoelectron spectroscopy (XPS) measurements, three distinct peaks corresponding to lattice oxygen, oxygen vacancies, and absorbed oxygen on the surface were identified. The XPS analysis results showed that oxygen vacancy defects on the $\mathrm{ZnO}$ nanorods were decreased by oxygen plasma treatment. Next, the effects of oxygen plasma on the elastic properties of $\mathrm{ZnO}$ nanorods were studied using lateral force microscopy. It was confirmed that the elastic modulus of $\mathrm{ZnO}$ nanorods increased due to the reduced number of defects originating from oxygen vacancies.
\end{abstract}

(Received December 21, 2020; Accepted January 19, 2021)

Keywords: zinc oxide, nanorod, oxygen plasma, lateral force microscopy, nanogenerator, piezoelectric

\section{Introduction}

Zinc oxide $(\mathrm{ZnO})$ is a II-VI compound semiconductor with a wurtzite structure that exhibits both semiconducting and piezoelectric properties [1,2]. A dense array of $\mathrm{ZnO}$ nanorods can be facilely grown using several synthesis methods $[3,4]$. In particular, $\mathrm{ZnO}$ nanorods can be grown in low-temperature conditions via hydrothermal synthesis, which makes this growth method suitable for use on flexible plastic substrates [5]. When stress is externally applied to vertically aligned $\mathrm{ZnO}$ nanorods, piezoelectric potential is generated via the deflection of the nanorods [6,7]. Diverse structures of piezoelectric nanogenerators have been developed based on

- 박동혁·양이준: 석사과정, 김관래: 교수

*Corresponding Author: Kwanlae Kim

[Tel: +82-2-970-7285, E-mail: klkim@seoultech.ac.kr]

Copyright (c) The Korean Institute of Metals and Materials this electromechanical coupling effect in $\mathrm{ZnO}$ nanorods [8].

The performance of a piezoelectric nanogenerator based on $\mathrm{ZnO}$ nanorods can be enhanced via several approaches. For instance, the output electrical energy from vertically grown $\mathrm{ZnO}$ nanorods can be improved by optimizing the aspect ratio of the $\mathrm{ZnO}$ nanorods $[9,10]$. The crystal quality and piezoelectric power generation are dependent on the growth method used [11]. Furthermore, a piezoelectric nanogenerator based on $\mathrm{ZnO}$ nanorods is sensitively influenced by oxygen and humidity levels [12]. For instance, oxygen plasma treatment can reduce the charge carrier concentration, enhancing the generation of piezoelectric potential [13].

With oxygen plasma treatment, the oxygen vacancies on the surface of $\mathrm{ZnO}$ nanorods become filled by oxygen molecules combining with free electrons to form oxygen ions [12]. During this process, the elastic property of the $\mathrm{ZnO}$ nanorods can be altered. The effects of oxygen plasma on the 
mechanical properties of $\mathrm{ZnO}$ nanorods has been investigated using a nanoindentation method, and the results showed that the stiffness of $\mathrm{ZnO}$ nanorods can be enhanced by such treatment [14]. However, given the size of $\mathrm{ZnO}$ nanorods, a more precise and suitable measurement method is required to evaluate changes in the elastic properties of $\mathrm{ZnO}$ nanorods.

Atomic force microscopy (AFM) has been preferentially used to characterize the mechanical and piezoelectric properties of $\mathrm{ZnO}$ nanorods [7,15]. A typical AFM tip has a radius of less than $100 \mathrm{~nm}$ and is hence suitable for measuring and manipulating individual $\mathrm{ZnO}$ nanorods. Conductive AFM [7] and piezoresponse force microscopy (PFM) [16] have been effectively used to study the piezoelectric properties of $\mathrm{ZnO}$ nanorods via direct and inverse piezoelectric effects, respectively. In addition, when operating AFM in contact mode on vertically aligned $\mathrm{ZnO}$ nanorods, the enhanced stiffness of the $\mathrm{ZnO}$ nanorods can be precisely measured by lateral force microscopy (LFM) [15]. LFM is commonly used to measure friction force on the microscale by monitoring the degree of torsion in the AFM cantilever [17]. This working principle can be effectively exploited to monitor changes in the elastic properties of free-standing $\mathrm{ZnO}$ nanorods after an oxygen plasma treatment.

In the present study, we investigated the effects of oxygen plasma on a dense array of $\mathrm{ZnO}$ nanorods using LFM. First of all, the change in the surface roughness of the $\mathrm{ZnO}$ nanorods by oxygen plasma etching was analyzed using AFM topography images. Then, changes in the elemental composition and microstructure of the $\mathrm{ZnO}$ nanorods caused by oxygen plasma were analyzed by X-ray photoelectron spectroscopy (XPS) and X-ray diffraction (XRD), respectively. Finally, the effects of oxygen plasma on the elastic properties of $\mathrm{ZnO}$ nanorods were studied using LFM.

\section{Experimental Methods}

$\mathrm{ZnO}$ nanorods were hydrothermally grown on a $p$-type silicon wafer substrate by seed layer formation and a subsequent nanowire growth process [18]. First, the silicon wafer was ultrasonically cleaned using acetone, ethyl alcohol, and deionized water for $10 \mathrm{~min}$ each, in sequence. To form the seed layer, a cleaned silicon wafer was immersed in a solution of $50 \mathrm{mM}$ zinc acetate dihydrate [ $\mathrm{Zn}(\mathrm{CH} 3 \mathrm{COO}) 2 \cdot 2 \mathrm{H} 2 \mathrm{O}$ ]

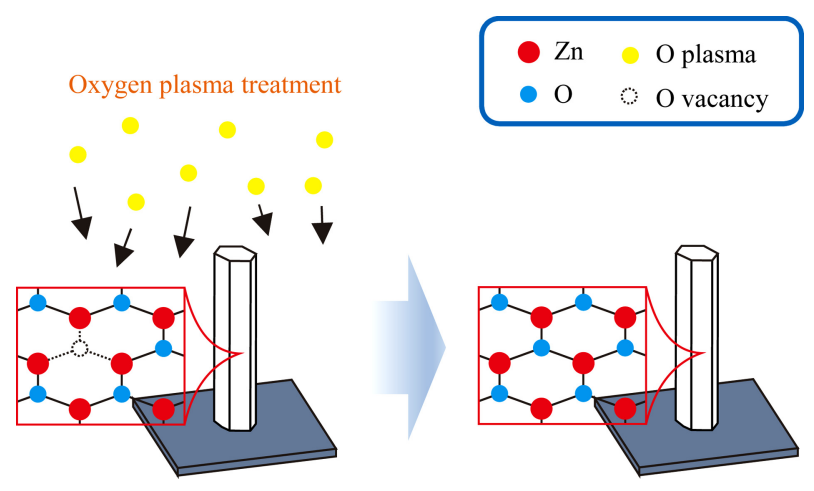

Fig. 1. Schematic of the oxygen plasma treatment of a $\mathrm{ZnO}$ nanorod. Oxygen vacancies of a $\mathrm{ZnO}$ nanorod are filled with reactive oxygen, combining with free electrons to form oxygen ions.

(Samchun, Korea) and ethyl alcohol at $80{ }^{\circ} \mathrm{C}$ for $30 \mathrm{~s}$, and then subsequently annealed at $100{ }^{\circ} \mathrm{C}$ for $5 \mathrm{~min}$ in air. The seed layer formation process was repeated three times. The $\mathrm{ZnO}$ nanorods were then synthesized at a 1:1 molar ratio of zinc nitrate hexahydrate [ $\mathrm{Zn}(\mathrm{NO} 3) 2 \cdot 6 \mathrm{H} 2 \mathrm{O}]$ (Samchun, Korea) and hexamethylenetetramine [(CH2)6N4] (HMTA, Kanto, Japan) in a $50 \mathrm{mM}$ precursor solution with deionized water at $80^{\circ} \mathrm{C}$ for $24 \mathrm{~h}$. Finally, the $\mathrm{ZnO}$ nanorods grown on the silicon wafer were cleaned with deionized water to remove any residual particles on the surface.

The $\mathrm{ZnO}$ nanorods were treated with oxygen plasma using a RF magnetron sputtering system. The oxygen plasma treatment was intended to reduce oxygen vacancies, as reactive oxygen plasma diffuses through $\mathrm{ZnO}$ nanorod surfaces and traps electrons, as depicted in Fig. 1 [19,20]. The surface wettability of the $\mathrm{ZnO}$ nanorods was photographed using a contact angle meter (CAM-200, KSV). The surface morphology of the $\mathrm{ZnO}$ nanorods was observed using a field emission scanning electron microscope (FE-SEM, JSM$6700 \mathrm{~F}$, Jeol). XRD patterns of the $\mathrm{ZnO}$ nanorods on the silicon wafer were obtained using an X-ray diffractometer (DE/D8 Advance, Bruker) with $\mathrm{Cu}-\mathrm{K} \alpha$ radiation. The XPS spectra of the $\mathrm{ZnO}$ nanorods were measured using a high-performance X-ray spectroscopy (HP-XPS, K-Alpha ${ }^{+}$, Thermo Fisher Scientific). The XPS spectra were analyzed by peak fitting software (Avantage Data System, Thermo Fisher Scientific). LFM and surface roughness measurements were conducted using an AFM (XE-150, Park Systems). The topography signals originate from error signals in the feedback circuit, 
and LFM signals are generated from the torsional behavior of the cantilever detected via a position-sensitive photodetector (PSPD) (see Fig. 2). To measure lateral force and surface roughness, two distinct AFM probes were chosen, based on their spring constants. To fully deflect nanorods, an AFM probe with a large spring constant is required. On the other hand, it is necessary to avoid deflecting nanorods to accurately measure the surface roughness of nanorods. Accordingly, the AFM probes PPP-NCHPt $(42.0 \mathrm{~N} / \mathrm{m})$ and ElectriCont-G $(0.2 \mathrm{~N} / \mathrm{m})$ were used to measure lateral force and surface roughness, respectively. LFM measurements were taken at a normal force level of $420 \mathrm{nN}$ and a frequency of $0.2 \mathrm{~Hz}$. To measure the surface roughness of the $\mathrm{ZnO}$ nanorods, AFM scans were conducted at a normal force level of $10 \mathrm{nN}$ and frequency of $0.2 \mathrm{~Hz}$ to minimize deflections of the vertically aligned $\mathrm{ZnO}$ nanorods.

It should be noted that even though LFM measurements were carried out on a densely grown $\mathrm{ZnO}$ nanorod array, the spring constant of the AFM probe (NCHPt) and the set point were large enough to sufficiently deflect the nanorods. When the AFM probe scans the $\mathrm{ZnO}$ nanorods, there can be interference between the nanorod deflected by the AFM tip and the neighboring nanorods, to some extent. Thus, the LFM signals measured from an array of nanorods can be considerably influenced by the density of the nanorod array.

\section{Results and Discussion}

Fig. 3 (a) and (b) shows the contact angles of the as-grown and oxygen-plasma-treated $\mathrm{ZnO}$ nanorods, respectively, as measured by a sessile-drop goniometry technique. The
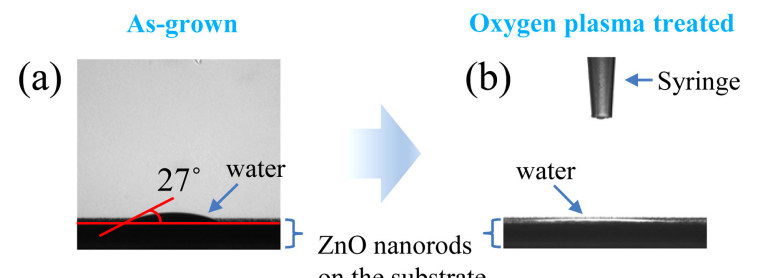

(c)

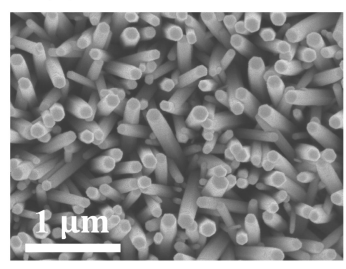

(e)
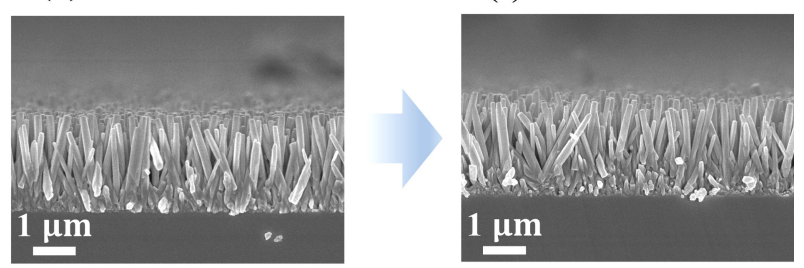

Fig. 3. The surface wettability of $\mathrm{ZnO}$ nanorods was evaluated by a contact angle meter (a) before and (b) after the oxygen plasma treatment. Top view of $\mathrm{ZnO}$ nanorods (c) before and (d) after the oxygen plasma treatment, and side view of $\mathrm{ZnO}$ nanorods (c) before and (d) after the oxygen plasma treatment.

contact angle $\left(\theta_{c}\right)$ is defined as the angle between the top surface of the substrate and a line tangent to the water-air interface [21]. Approximately $1.5 \mu \mathrm{l}$ of water droplets were dispensed onto the $\mathrm{ZnO}$ nanorod sample surfaces, and after $2-3$ seconds for stabilization, images were then captured. A water droplet dispensed on an as-grown $\mathrm{ZnO}$ nanorod sample shows hydrophilicity $\left(\theta_{c}=27^{\circ}\right)$ resulting from the presence of $\mathrm{Zn}$ cations, $\mathrm{O}$ anions, and $\mathrm{OH}$ groups on the surface [22].
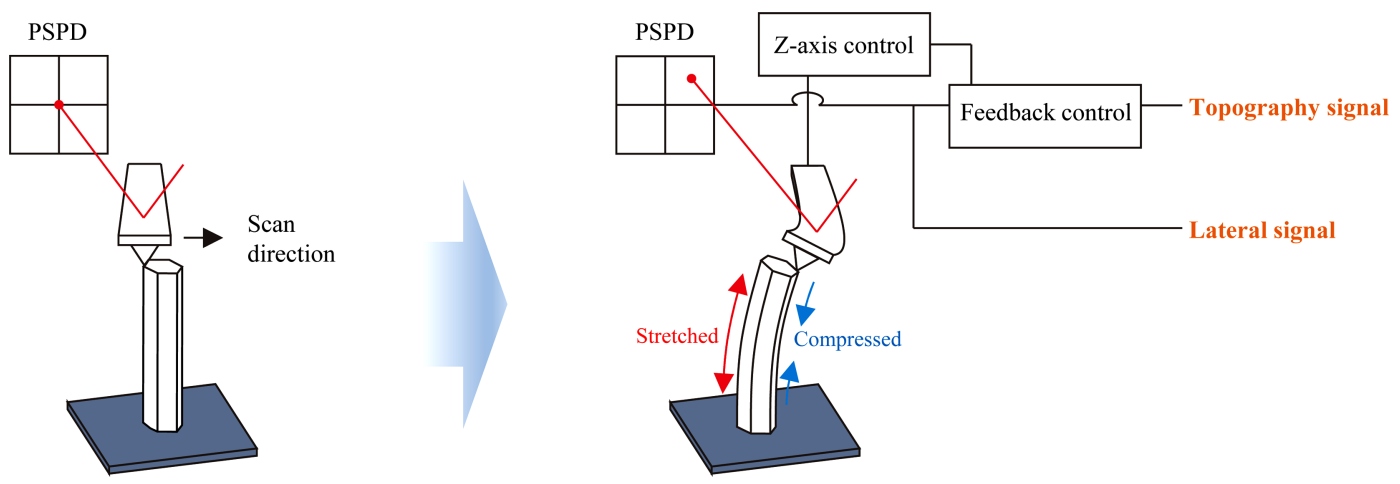

Fig. 2. Schematic of the imaging of a $\mathrm{ZnO}$ nanorod using lateral force microscopy. When the AFM probe scans a free-standing $\mathrm{ZnO}$ nanorod, it deflects the nanorod due to the finite response time in the feedback circuit. The torsional behavior of the cantilever is monitored by the PSPD, producing LFM signals. 
However, the spread of a water droplet on an oxygen-plasmatreated $\mathrm{ZnO}$ nanorod sample exhibited a significantly low contact angle. This enhanced hydrophilicity implies that the surface roughness and oxidation were enhanced by the oxygen plasma treatment $[23,24]$, as investigated further by AFM (Fig. 4) and XPS (Fig. 6).

Meanwhile, Fig. 3(c) and (e) show a top and a side view of the as-grown $\mathrm{ZnO}$ nanorods, respectively. Fig. 3(d) and (f) correspondingly depict a top and a side view of the oxygenplasma-treated $\mathrm{ZnO}$ nanorods, respectively. Both the asgrown and oxygen-plasma-treated $\mathrm{ZnO}$ samples clearly exhibit the formation of nanorods. As indicated in Fig. 3(e) and (f), both the as-grown and oxygen-plasma-treated $\mathrm{ZnO}$ nanorods are well aligned perpendicular to the substrate. There was no remarkable change in the morphological characteristics after the oxygen plasma treatment, that is, the diameter, length, and alignment were not affected by the oxygen plasma.

Since the effect of oxygen plasma treatment on the surfaces of $\mathrm{ZnO}$ nanorods could not be clearly observed in the SEM

(a) As grown

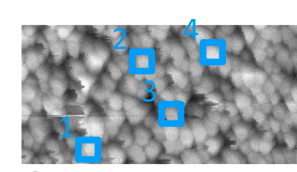
$2 \mu \mathrm{m}$

\section{(c)}

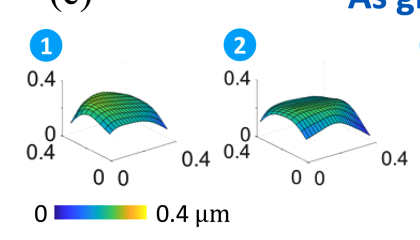

As grown

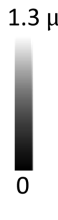

(b) Oxygen plasma treated

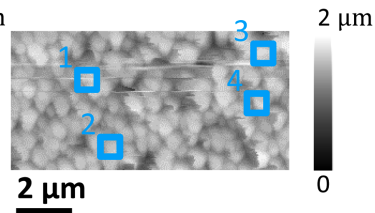

$2 \mu \mathrm{m}$

(d)

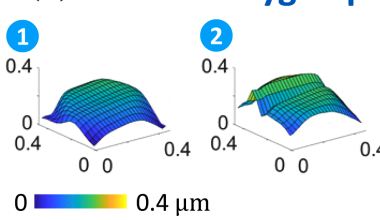

Fig. 4. Surface roughness measurements of $\mathrm{ZnO}$ nanorods. AFM topography images (a) before and (b) after the oxygen plasma treatment. The small areas marked by rectangles in (a) and (b) were reproduced using Matlab in three-dimensional images in (c) and (d). The numbers " 1 " - " 4 " in (c) and (d) indicate their corresponding rectangular areas in (a) and (b), respectively. images, we measured the surface roughness of the $\mathrm{ZnO}$ nanorods using AFM. This is because the etching effect of oxygen plasma may be observed in a subtle morphological change in the surface of the $\mathrm{ZnO}$ nanorods. As mentioned earlier, AFM was operated in contact mode in a scan condition with a normal force of $10 \mathrm{nN}$ and a frequency of $0.2 \mathrm{~Hz}$ to obtain optimal topography images of free-standing $\mathrm{ZnO}$ nanorods. Fig. 4(a) and (b) shows the topographic images of the $\mathrm{ZnO}$ nanorods before and after the oxygen plasma treatment, respectively.

To evaluate the change in surface roughness caused by the oxygen plasma treatment, four areas were selected from the top surfaces of the $\mathrm{ZnO}$ nanorods, as marked in Fig. 4(a) and (b). Subsequently, the topographical data of the as-grown and oxygen-plasma-treated $\mathrm{ZnO}$ nanorods were reproduced as three-dimensional images (see Fig. 4(c) and (d)). These images indicate that the surface roughness of the $\mathrm{ZnO}$ nanorods was increased by the oxygen plasma treatment. For a quantitative analysis of the surface roughness, the rootmean-square (RMS) roughness was computed for these local regions. Table 1 shows that the RMS roughness values of the oxygen-plasma-treated sample were larger overall than those of the as-grown sample.

An important effect of oxygen plasma is surface etching by ion bombardment [25]. In an earlier work [26], oxygen plasma was applied to $\mathrm{ZnO}$ films and the surface roughness increased because the surface particles were etched. The increased RMS roughness of the $\mathrm{ZnO}$ nanorods here can also be explained by this etching effect.

Fig. 5 shows the XRD patterns of as-grown and oxygenplasma-treated $\mathrm{ZnO}$ nanorods. The intensity scales were adjusted based on the (002) peak for a comparative analysis, showing a strong preferential c-axis orientation, as indicated by the (002) peak. In the XRD patterns, both the as-grown and oxygen-plasma-treated $\mathrm{ZnO}$ nanorods exhibit a hexagonal crystal system, a wurtzite structure, which can be confirmed by the (100), (002), (101) peaks at 2 theta $=31.8^{\circ}, 34.4^{\circ}$, and

Table 1. RMS surface roughness values for the four local areas in Figs. 4(a) and (b) (unit: $\mu \mathrm{m}$ ).

\begin{tabular}{ccccc}
\hline & No. 1 & No. 2 & No. 3 & No. 4 \\
\hline As-grown & 0.2634 & 0.3015 & 0.3044 & 0.2412 \\
Oxygen plasma treated & 0.4008 & 0.4076 & 0.3620 & 0.4015 \\
\hline
\end{tabular}



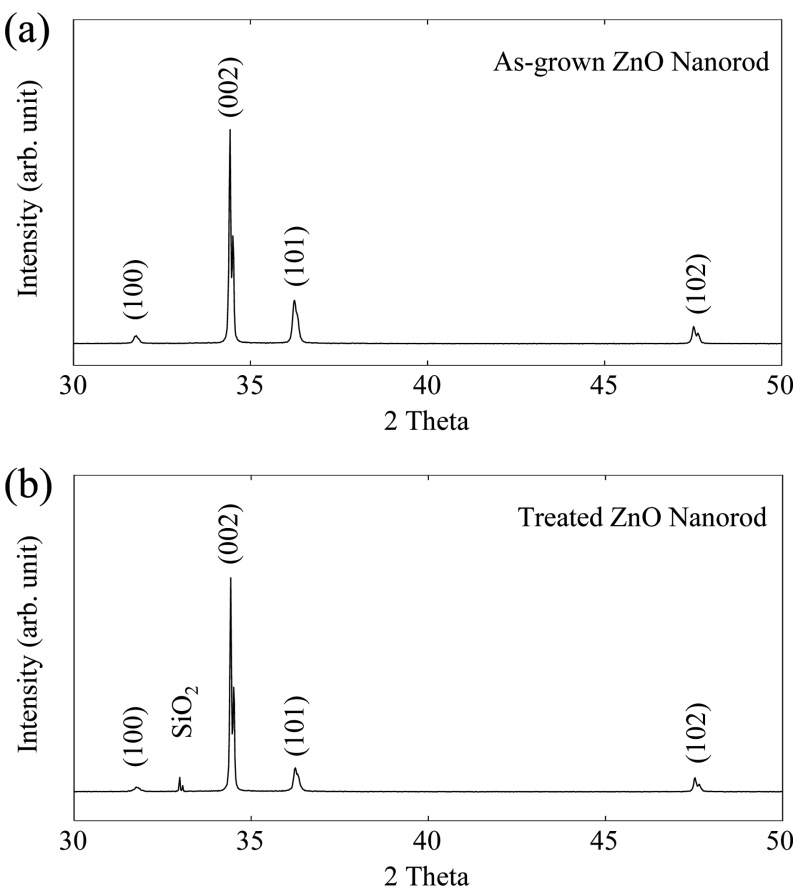

Fig. 5. XRD measurements of the $\mathrm{ZnO}$ nanorods. $\mathrm{XRD}$ profiles of the $\mathrm{ZnO}$ nanorods (a) before and (b) after the oxygen plasma treatment.

$36.2^{\circ}$, respectively [27]. Except for the $\mathrm{SiO}_{2}$ peak in Fig. 5(b) originating from the silicon substrate, there were no remarkable peak shifts in the XRD patterns between the asgrown and oxygen-plasma-treated $\mathrm{ZnO}$ nanorods. Thus, it could be verified that no phase transition of the $\mathrm{ZnO}$ nanorods was induced by the oxygen plasma treatment.

The full width at half maximum (FWHM) of the as-grown and oxygen-plasma-treated $\mathrm{ZnO}$ nanorods in the (002) reflection were $0.06^{\circ}$ and $0.054^{\circ}$, respectively. This decrease in FWHM indicates an improvement in the crystallinity, which was attributed to new $\mathrm{Zn}-\mathrm{O}$ bonds with fewer oxygen vacancies.

Fig. 6 presents the XPS spectra of the as-grown and oxygen-plasma-treated $\mathrm{ZnO}$ nanorods to clarify their chemical composition and elemental state. Fig. 6(a) shows the XPS analysis results of the zinc, oxygen, and reference carbon elements. The $\mathrm{Zn} 2 \mathrm{p}$ regions and $\mathrm{O} 1 \mathrm{~s}$ peaks are highlighted in Figs. 6(b) and (c), respectively. From Fig. 6(b), the $\mathrm{Zn} 2 \mathrm{p}_{3 / 2}$ and $\mathrm{Zn} 2 \mathrm{p}_{1 / 2}$ peaks located at $\sim 1021.38 \mathrm{eV}$ and $\sim 1044.53 \mathrm{eV}$, respectively, can be observed. The binding energy differences $(\sim 23 \mathrm{eV})$ between the $\mathrm{Zn} 2 \mathrm{p}_{3 / 2}$ and the $\mathrm{Zn}$
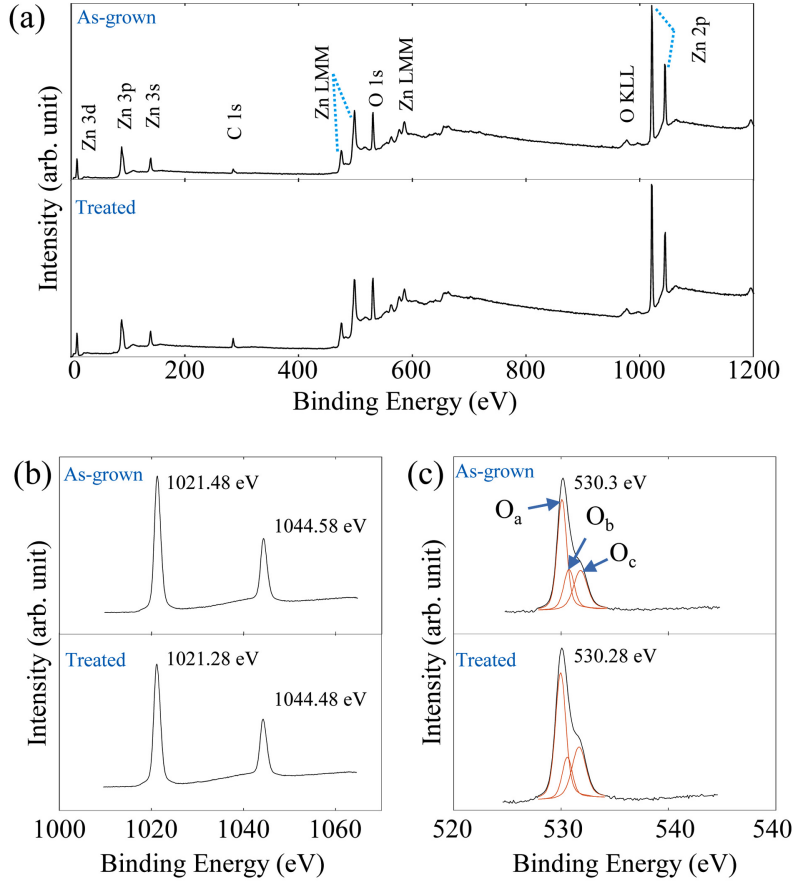

Fig. 6. XPS measurements of the $\mathrm{ZnO}$ nanorods: (a) XPS spectra of $\mathrm{ZnO}$ nanorods before and after the oxygen plasma treatment. (b) $\mathrm{Zn}$ $2 \mathrm{p}$ regions and (c) $\mathrm{O} 1 \mathrm{~s}$ peaks before and after the oxygen plasma treatment are highlighted.

$2 \mathrm{p}_{1 / 2}$ peaks in the as-grown and oxygen-plasma-treated $\mathrm{ZnO}$ nanorods indicate the $\mathrm{Zn}^{2+}$ oxidation state $[28,29]$.

Fig. 6(c) displays the XPS spectra of the O 1s core levels with oxygen-dependent defects. The three fitted peaks at $\sim 530.1 \mathrm{eV}, \sim 530.5 \mathrm{eV}$ and $\sim 531.9 \mathrm{eV}$ correspond to lattice oxygen $\left(\mathrm{O}_{\mathrm{a}}\right)$, an oxygen vacancy $\left(\mathrm{O}_{\mathrm{b}}\right)$, and absorbed oxygen on the surface $\left(\mathrm{O}_{c}\right)$, respectively $[30,31]$. To analyze the effects of oxygen plasma on the XPS peak originating from oxygen vacancies, the area ratio of $\mathrm{O}_{b}$ to $\mathrm{O}_{\mathrm{a}}$ was compared using a published method [32].

$$
A_{\mathrm{b}}=\frac{\text { Area of peak } \mathrm{O}_{\mathrm{b}}}{\text { Area of peak } \mathrm{O}_{\mathrm{a}}+\text { Area of peak } \mathrm{O}_{\mathrm{b}}}
$$

Here, the $A_{\mathrm{b}}$ values of the as-grown and oxygen-plasmatreated $\mathrm{ZnO}$ nanorods were 0.29 and 0.24 , respectively. This decrease indicates that oxygen vacancy defects were decreased by the oxygen plasma treatment $[14,32]$.

To observe the effects of the oxygen plasma on the elastic properties of the $\mathrm{ZnO}$ nanorods, LFM measurements were taken of the as-grown and oxygen-plasma-treated $\mathrm{ZnO}$ nanorods. Fig. 7(a) and (b) show histograms of the LFM 
(a)
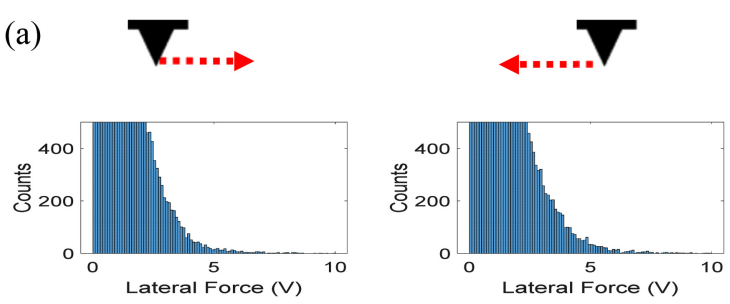

Oxygen plasma treatment

(b)
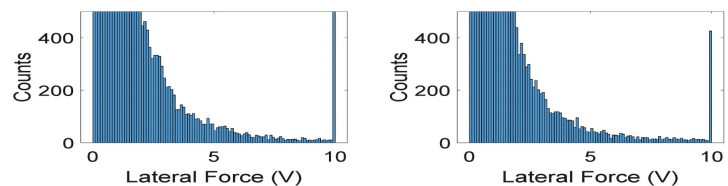

(c)

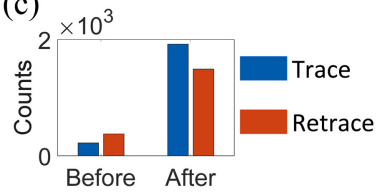

Fig. 7. Statistical analysis of the LFM measurements on the $\mathrm{ZnO}$ nanorods: (a) counts vs. LFM signals during trace and retrace scans, (b) counts vs. LFM signals during trace and retrace scans after the oxygen plasma treatment, and (c) total counts of the LFM signals of $>5 \mathrm{~V}$ during trace and retrace scans before and after the oxygen plasma treatment.

signals obtained during trace and retrace scans for the as-grown and oxygen-plasma-treated $\mathrm{ZnO}$ nanorods, respectively. To represent counts of $>5 \mathrm{~V}$ effectively, all of the histograms are shown in a $0-500$ count range. With regard to the LFM measurements, in each case $512 \times 128$ data points were obtained from a $10 \mu \mathrm{m} \times 5 \mu \mathrm{m}$ area.

It should be noted that LFM signals are positive and negative during trace and retrace scans, respectively. Thus, absolute values were used in Fig. 7. Fig. 7(a) and (b) indicate that the counts corresponding to the LFM signals of $>5 \mathrm{~V}$ increased after the oxygen plasma treatment. The total counts for the signals of $>5 \mathrm{~V}$ are presented in Fig. 7(c), which shows remarkable increases after the oxygen plasma treatment.

In addition, the counts corresponding to the maximum LFM signal $(10 \mathrm{~V})$ increased from 1 (trace) and 1 (retrace) to 664 (trace) and 410 (retrace) due to the oxygen plasma treatment. It should be noted that in the present study raw LFM signals were used to evaluate the enhanced elastic property of the $\mathrm{ZnO}$ nanorods, but these voltage signals can be converted into the unit of force through several force calibration methods [33]. Additionally, in the AFM instrument used in the present study measurable LFM signals are in the range of $0-10 \mathrm{~V}$. Thus, all the LFM signals larger than $10 \mathrm{~V}$ were also represented as $10 \mathrm{~V}$.

Increased LFM signals from the $\mathrm{ZnO}$ nanorods due to the oxygen plasma treatment can be observed in the results of the statistical analysis shown in Fig. 7, and can also be confirmed from the three-dimensional LFM images in Fig. 8. Fig. 8(a) presents LFM images obtained from the as-grown $\mathrm{ZnO}$ nanorods during trace and retrace scans, and Fig. 8(b) shows them after the oxygen plasma treatment. First, it is evident that, overall, the LFM signals increased after the oxygen plasma treatment. In the as-grown sample, LFM signals near $10 \mathrm{~V}$ were detected from only a few $\mathrm{ZnO}$ nanorods. However, after the oxygen plasma treatment, LFM signals at $10 \mathrm{~V}$ could be observed from several $\mathrm{ZnO}$ nanorods. It should be noted that the LFM measurement results shown in Fig. 7 and Fig. 8 are different depending on the scan direction. This is attributed to the deflection of the $\mathrm{ZnO}$ nanorods during the growth process. As can be seen from Fig. 3, individual $\mathrm{ZnO}$ nanorods tend to randomly deflect during the hydrothermal synthesis. Thus, during LFM measurements, the deflection of $\mathrm{ZnO}$ nanorods by the AFM tip would differ depending on the scan direction, resulting in the different LFM images from the trace and retrace scans.

An LFM signal originates from the torsional behavior of the AFM cantilever. The increase in LFM signals from the $\mathrm{ZnO}$ nanorods caused by the oxygen plasma treatment can be explained by the relationship between the elastic modulus and the applied lateral force. This is expressed by the following equation [15],

$$
f=3 E I \frac{x}{L^{3}}
$$

where $f$ is the lateral force applied to a $\mathrm{ZnO}$ nanorod, $E$ is the elastic modulus, $I$ is the moment of inertia, $x$ is the lateral displacement, and $L$ is the length of a $\mathrm{ZnO}$ nanorod. Given that the effect of oxygen plasma on the morphology of the $\mathrm{ZnO}$ nanorods is almost negligible, the increase in $f$ is caused by the enhanced $E$. This enhancement of elastic property by oxygen plasma can be explained by the reduction in the number of defects associated with oxygen vacancies [14].

It should be noted that oxygen plasma treatment was carried out using a substrate bias method in the magnetron 

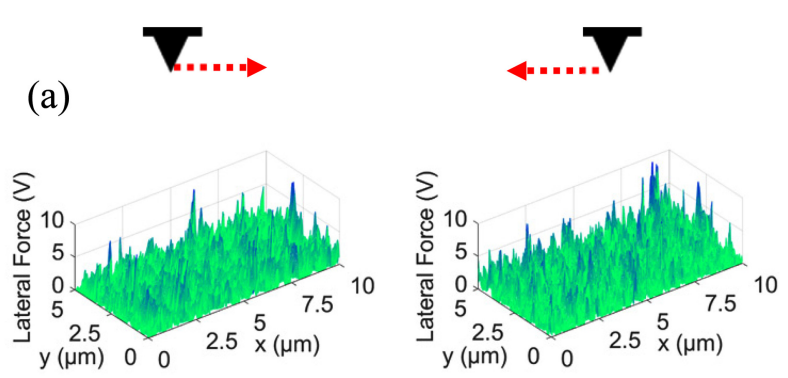

Oxygen plasma treatment

(b)
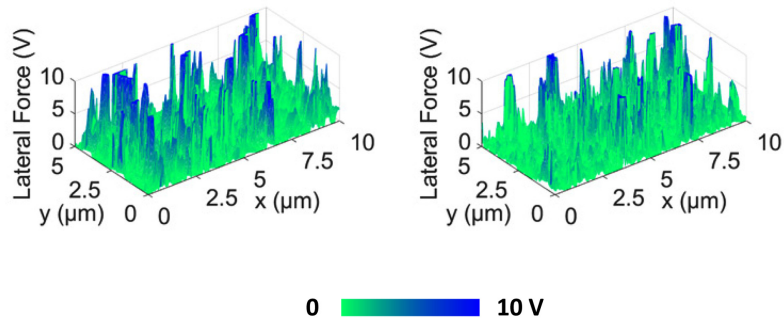

Fig. 8. Three-dimensional LFM images: (a) LFM images were obtained during trace and retrace scans before the oxygen plasma treatment and (b) after the oxygen plasma treatment.

sputtering system, as stated in the Experimental methods section. Given the thickness of the $\mathrm{ZnO}$ nanorod layer $(2-3 \mu \mathrm{m})$ and the dense array of nanorods, it is speculated that the upper parts of the nanorods were more influenced by oxygen plasma treatment than the nanorods' sidewalls. However, in the present study, the chemical and structural analyses using XPS and XRD to investigate the local effect of oxygen plasma treatment on $\mathrm{ZnO}$ nanorods were constrained, due to insufficient measurement resolution. The etching efficiency of the oxygen plasma can differ on the top surface and the sidewall of a nanorod. With the $\mathrm{ZnO}$ nanorod samples grown by the hydrothermal synthesis method used in the present study, obtaining an accurate surface roughness for the sidewall of a $\mathrm{ZnO}$ nanorod is difficult, given the densely grown nanorod array. Measuring the local surface roughness of nanorods would be possible only for a much less densely grown nanorod sample. Meanwhile, Li et al. [34] has reported that the upper parts of $\mathrm{ZnO}$ nanorods were preferentially etched by Ar plasma treatment. However, no such differential etching rate of oxygen plasma treatment on $\mathrm{ZnO}$ nanorods was reported in the previous work by Hussain et al. [14], and it was not clearly observed in the SEM images (Figs. 3(c)-(f)) of the present study.

In summary, the critical effect of oxygen plasma treatment on the mechanical properties of $\mathrm{ZnO}$ nanorods is the filling of oxygen vacancies with reactive oxygen. This was confirmed by the $\mathrm{O}$ 1s peak analysis in the XPS spectra; the $\mathrm{A}_{b}$ in Eq. (1) decreased from 0.29 to 0.24 , indicating new $\mathrm{Zn}$ $\mathrm{O}$ bonding. The reduced oxygen vacancies were also confirmed via structural analysis using XRD. Improved crystallinity was observed in the $\mathrm{ZnO}$ nanorods based on the decrease in FWHM in the (002) peak (from $0.06^{\circ}$ to $0.054^{\circ}$ ). This enhancement in crystallinity by oxygen plasma is responsible for the enhanced elastic property of the $\mathrm{ZnO}$ nanorods, which was clearly confirmed by the significant increase in the number of LFM signals $>5 \mathrm{~V}$. The quantitative analyses results of the chemical, structural, and mechanical properties are summarized in Table 2.

\section{Conclusion}

An oxygen plasma treatment was conducted on a dense array of $\mathrm{ZnO}$ nanorods grown via a two-step hydrothermal synthesis process, using a RF magnetron sputtering system. No noticeable change in the morphology of the $\mathrm{ZnO}$ nanorods was observed after the oxygen plasma treatment. However, an increase in the surface roughness of the $\mathrm{ZnO}$ nanorods was caused by the etching effect of oxygen plasma, as confirmed by the increase in the RMS roughness measured via AFM topography images. Meanwhile, from XRD measurements, no significant peak shift was detected after the oxygen plasma treatment, except for a peak originating from the oxidized silicon substrate. The results of contact angle measurements showed that the hydrophilicity of the

Table 2. The effect of oxygen plasma on the chemical, structural, and mechanical properties of $\mathrm{ZnO}$ nanorods.

\begin{tabular}{cccc}
\hline Analysis method (Characterization method) & Chemical (XPS) & Structural (XRD) & Mechanical (LFM) \\
\hline Evaluation criteria & $\mathbf{A}_{\mathbf{b}}$ & FWHM at (002) & No. of LFM signals $>\mathbf{5 ~ V}$ \\
As-grown & 0.29 & $0.06^{\circ}$ & 1 (trace), 1 (retrace) \\
Oxygen plasma treated & 0.24 & $0.054^{\circ}$ & 664 (trace), 410 (retrace) \\
\hline
\end{tabular}


$\mathrm{ZnO}$ nanorods was increased by oxygen plasma, implying that the surface oxidation and roughness were enhanced. An XPS analysis of the chemical composition found that oxygen vacancies in the $\mathrm{ZnO}$ nanorods were decreased by oxygen plasma. LFM measurements were taken on vertically aligned $\mathrm{ZnO}$ nanorods, and the degree of torsion in the AFM cantilever was monitored during trace and retrace scans. Overall, the LFM signals increased and the number of signals near the maximum LFM signal level $(10 \mathrm{~V})$ increased significantly after the oxygen plasma treatment. The increase in the elastic modulus of the $\mathrm{ZnO}$ nanorods by oxygen plasma was induced by the reduced number of defects associated with oxygen vacancies.

\section{Acknowledgement}

This study was supported by the Research Program funded by the SeoulTech(Seoul National University of Science and Technology).

\section{REFERENCES}

1. Z. L. Wang, J. Phys. Condens. Matter 16, R829 (2004).

2. Ü. Özgür, Y. I. Alivov, C. Liu, A. Teke, M. A. Reshchikov, S. Doğan, V. Avrutin, S.-J. Cho, and H. Morkoç, J. Appl. Phys. 98, 041301 (2005).

3. S. Oh, H. Ryu, and W.-J. Lee, Korean J. Met. Mater. 55, 255 (2017).

4. J. Y. Park and S. S. Kim, Met. Mater. Int. 14, 357 (2008).

5. L. Schmidt-Mende and J. L. MacManus-Driscoll, Mater Today 10, 40 (2007).

6. J. Song, J. Zhou, and Z. L. Wang, Nano Lett. 6, 1656 (2006).

7. Z. L. Wang and J. Song, Science, 312, 242 (2006).

8. F. R. Fan, W. Tang, and Z. L. Wang, Adv. Mater. 28, 4283 (2016).

9. R. Hinchet, S. Lee, G. Ardila, L. Montès, M. Mouis, and Z. L. Wang, Adv. Funct. Mater. 24, 971 (2014).

10. V. F. Rivera, F. Auras, P. Motto, S. Stassi, G. Canavese, E. Celasco, T. Bein, B. Onida, and V. Cauda, Chem. Eur. J. 19, 14665 (2013).

11. M. Riaz, J. Song, O. Nur, Z. L. Wang, and M. Willander, Adv. Funct. Mater. 21, 628 (2011).

12. V. Nguyen, R. Zhu, and R. Yang, Nano Energy 14, 49 (2015).

13. Y. Hu, L. Lin, Y. Zhang, and Z. L. Wang, Adv. Mater. 24,
110 (2012).

14. M. Hussain, A. Khan, O. Nur, M. Willander, and E. Broitman, Chem. Phys. Lett. 608, 235 (2014).

15. J. Song, X. Wang, E. Riedo, and Z. L. Wang, Nano Lett. 5, 1954 (2005).

16. J. Xiao, W. L. Ong, Z. Guo, G. W. Ho, and K. Zeng, ACS Appl. Mater. Interfaces 7, 11412 (2015).

17. B. Bhushan, Wear 259, 1507 (2005).

18. Y. Yang and K. Kim, Korean J. Met. Mater. 58, 67 (2020).

19. H.-W. Ra and Y.-H. Im, Nanotechnology 19, 4 (2008).

20. H. Faber, J. Hirschmann, M. Klaumünzer, B. Braunschweig, W. Peukert, and M. Halik, ACS Appl. Mater. Interfaces 4, 1693 (2012).

21. T. Huhtamäki, X. Tian, J. T. Korhonen, and R. H. A. Ras, Nat. Protoc. 13, 1521 (2018).

22. J. Bae, I. A. Samek, P. C. Stair, and R. Q. Snurr, Langmuir 35, 5762 (2019).

23. R. Sliz, Y. Suzuki, A. Nathan, R. Myllyla, and G. Jabbour, Proc. SPIE 8477 (eds. Z. H. Kafafi, C. J. Brabec, and P. A. Lane), p. 84771G-1, Int. Soc. Opt. Photonics, California, United States (2012).

24. J.-B. Han, X. Wang, N. Wang, Z.-H. Wei, G.-P. Yu, Z.-G. Zhou, and Q.-Q. Wang, Surf. Coat. Technol. 200, 4876 (2006).

25. M. R. Sanchis, O. Calvo, O. Fenollar, D. Garcia, and R. Balart, J. Appl. Polym. Sci. 105, 1077 (2007).

26. J. S. Meena, M.-C. Chu, Y.-C. Chang, H.-C. You, R. Singh, P.-T. Liu, H.-P. D. Shieh, F.-C. Chang, and F.-H. Ko, J. Mater. Chem. C 1, 6613 (2013).

27. R. M. Wang, Y. J. Xing, J. Xu, and D. P. Yu, New J. Phys. 5, 115 (2003).

28. Z.-W. Wu, S.-L. Tyan, H.-H. Chen, J.-C.-A. Huang, Y.-C. Huang, C.-R. Lee, and T.-S. Mo, Superlattice. Microst. 107, 38 (2017).

29. R. Ahmad, N. Tripathy, M. Y. Khan, K. S. Bhat, M.-S. Ahn, and Y.-B. Hahn, RSC Adv. 6, 54836 (2016).

30. H. Yin, K. Yu, C. Song, Z. Wang, and Z. Zhu, Nanoscale 6, 11820 (2014).

31. Y. Tu, S. Chen, X. Li, J. Gorbaciova, W. P. Gillin, S. Krause, and J. Briscoe, J. Mater. Chem. C 6, 1815 (2018).

32. M. M. Can, S. I. Shah, M. F. Doty, C. R. Haughn, and T. Firat, J. Phys. D Appl. Phys. 45, 195104 (2012).

33. M. Munz, J. Phys. D Appl. Phys. 43, 063001 (2010).

34. C. Li, G. Fang, L. Yuan, N. Liu, J. Li, D. Li, and X. Zhao, Appl. Surf. Sci. 253, 8478 (2007). 